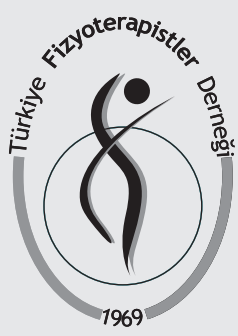

ISSN: 2651-4451 • e-ISSN: 2651-446X

\section{Turkish Journal of Physiotherapy and Rehabilitation}

$202031(1) 45-51$

Aslihan ÇAKMAK, MSc, PT Ebru ÇALIK KÜTÜKCÜ, PhD, PT Hülya ARIKAN, PhD, PT ${ }^{1}$

Naciye VARDAR YAĞLI, PhD, PT

Melda SAČLAM, PhD, PT

Deniz INAL INCE, PhD, PT

Çiğdem ÖKSÜZ, PhD, PT

Sema SAVCI, PhD, PT

Tülin DÜGER, PhD, PT

Cemile BOZDEMIR-ÖZEL, MSC, PT

Hazal SONBAHAR-ULU, MSC, PT'

Haluk TEKERLEK, PT

Lütfi ÇÖPLÜ, $M D^{4}$

\title{
THE DOSE INDEX IS RELATED WITH MUSCLE DYSFUNCTION, ACTIVITIES OF DAILY LIVING, AND QUALITY OF LIFE IN CHRONIC OBSTRUCTIVE PULMONARY DISEASE
}

\author{
ORIGINAL ARTICLE
}

\section{ABSTRACT}

Purpose: Composite measures have potential to account for many of the facets of disease in chronic obstructive pulmonary disease (COPD). The purpose of this study was to investigate the relationship between the DOSE (Dyspnea, Obstruction, Smoking, Exacerbation) Index which is a multi-component assessment tool and handgrip and respiratory muscle strength, activities of daily living (ADL) and health-related quality of life in patients COPD.

Methods: Forty-five patients with COPD (30 males, 15 females, mean FEV $=50.60 \pm 16.00 \%$ ) were included. The DOSE Index was calculated using the modified Medical Research Council dyspnea scale, obstruction level, smoking status, and exacerbation rate. Inspiratory and expiratory muscle strength (MIP and MEP) was measured using a mouth-pressure device. Handgrip strength was determined using hand dynamometer. Activities of daily living were evaluated using the London Chest Activity of Daily Living Scale (LCADL), and quality of life was assessed using the diseasespecific COPD Assessment Test (CAT).

Results: The DOSE Index score was related with handgrip strength $(r=-0.388, p=0.009)$, MIP ( $r=-$ $0.323, p=0.033)$, LCADL-physical activity score $(r=0.314, p=0.038)$, LCADL-leisure activities score $(r=0.397, p=0.008)$, and CAT score $(r=0.435, p=0.003)$.

Conclusion: Increased multi-component disease severity is related to decreased handgrip and respiratory muscle strength, physical activity and leisure time activities of daily living, and worse health-related quality of life in COPD patients. The DOSE Index, a simple disease severity assessment tool, is a convenient and practical tool for assessment in pulmonary rehabilitation programs.

Key Words: Activities of Daily Living; COPD; DOSE Index; Muscle Strength; Quality of Life.

\section{KRONIK OBSTRÜKTIF AKCIĞER HASTALIĞINDA DOSE INDEKSI KAS FONKSIYON BOZUKLUĞU, GÜNLÜK YAŞAM AKTIVITELERI VE YAŞAM KALITESI ILE íişKILIDiR} Hacettepe University, Faculty of Physical Therapy and
Rehabilitation, Ankara, Turkey. Ergotherapy, Ankara, Turkey. Dokuz Eylül University, School of Physiotherapy and Rehabilitation, Izmir, Turkey. 4Hacettepe University, Faculty of Medicine, Department of Chest Medicine, Ankara, Turkey.

\section{Correspondence (iletişim)}

Aslihan ÇAKMAK, MSC, PT Hacettepe University, Faculty of Physical Therapy and Rehabilitation 06100 Samanpazari, Ankara, Turkey Phone: +90-312-3051576-178 Fax: $+90-312-3052012$ E-mail: aslihancakmak90@gmail.com $0002-2474-8000$

Ebru ÇALIK KÜTÜKCÖ

ail.com, ORCID ID: 0000-0001-5215-5125 Hülya ARIKAN

harikan@hacettepe.edu.tr, ORCID ID: 0000-0002-0028-4256

naciyevardar@yahoo.com, ORCID ID: 0000-0003-0218-140X Melda SAĞLAM

ptmeldaozturk@yahoo.com, ORCID ID: 0000-0001-5323-1943

Deniz INAL INCE

dinalince@yahoo.com, ORCID ID: O000-0002-8151-0664
Çiğdem OKSÜZ

dinalince@yahoo.com, ORCID ID: 0000-0002-8151-0664
Çiğdem ÖKSÜZ

cigdemoksuz@yahoo.com, ORCID ID: 0000-0003-1840-8197 Sema SAVCI

sema.savci@yahoo.com.tr, ORCID ID: 0000-0001-8675-1937
Tülin DÜGER

sema.savci@yahoo.com.tr, ORCID ID: 0000-0001-8675-1937
Tülin DÜGER com, ORCID ID: 0000-0002-

Cemile BOZDEMIR ÖZEL

mail.com, ORCID ID: OODO-

Hazal SONBAHAR ULU

fzthaza@@gmail.com, ORCID ID: 0000-0002-7815-4072
Haluk TEKERLEK
haluktekerlek@gmail.com, ORCID ID: 0000-0003-4514-4801

Haluk TEKERLEK
haluktekerlek@gmail.com, ORCID ID: 0000-0003-4514-4801

Haluk TEKERLEK
haluktekerlek@gmail.com, ORCID ID: 0000-0003-4514-4801
Lütff CÖPLU

Lütfi ÇÖPLU

Icoplu@hacettepe.edu.tr. ORCID ID: 0000-0002-6961-7530

Recevied: 18.03.2019 (Geliş Tarihi)

Accepted: 30.06.2019 (Kabul Tarihi) 


\section{INTRODUCTION}

Chronic obstructive pulmonary disease (COPD) is a commonly seen, preventable, and treatable disease, which usually causes persistent airway symptoms and airflow limitation due to respiratory abnormalities (1). Besides inflammation in the pulmonary system, COPD is a multi-component disease that affects other bodily systems. Systemic inflammation induces the disruptive effects on extrapulmonary features such as skeletal muscle atrophy and dysfunction, and cardiovascular disease in patients with COPD (2).

Muscular dysfunction in COPD occurs due to pathophysiological changes, including altered bioenergetics, reduced muscle mass, altered capillarization, and fiber type redistribution. These changes result in physical manifestations, such as reduced strength and increased fatigue (3). These manifestations of COPD worsen the health status by causing respiratory and peripheral muscle dysfunction (4), limitations in activities of daily living (5), and quality of life (6).

There are several indices used in patients with COPD for assessing the severity of the disease. These indices are BODE Index (B: body mass index; $O$ : airflow obstruction; D: dyspnea; and E: exercise capacity), ADO Index (A-age; D-dyspnea, and O; obstruction) and DOSE Index (7). Considering the multi-componential nature of the disease, the DOSE Index was developed using four simple components consisting of the modified Medical Research Council Dyspnea Scale (MMRC) score (D), the airflow obstruction grade (O), the current smoking status (S), and the number of exacerbations (E) (8). The DOSE Index is a simple, valid tool to assess the disease severity, related to clinically relevant outcomes, and has guiding components for the management of COPD (8). Rolink et al. reported that the DOSE score of $\geq 4$ identifies patients with a higher risk of future worsening in COPDspecific health status in the following two years (9). However, to our knowledge, no research exists addressing the relationship between the DOSE 0 and muscle dysfunction, daily living activities, and quality of life in patients with COPD. Therefore, we aimed to investigate the association between the DOSE Index and handgrip and respiratory muscle strength, activities of daily living, and quality of life in patients with COPD.

\section{METHODS}

The present study was a cross-sectional study. The patients with COPD were recruited from Cardiopulmonary Rehabilitation Unit at the Department of Physical Therapy and Rehabilitation at Hacettepe University, Ankara, Turkey, between the years of 2013 and 2014. Patients diagnosed with COPD, aged between 40-80 years, without drug change for at least three weeks were determined as inclusion criteria. Exclusion criteria were having a musculoskeletal and neurological disease, symptomatic heart disease, undergoing previous pulmonary surgery, a malignant disease that may affect exercise performance, and unable to cooperate. Hacettepe University, Medical, Surgical, and Drug Research Ethical Committee approved this study (Approval Date: 28.08.2012 and Approval Number: LUT 12/56). All subjects provided written informed consent.

The characteristics of patients, such as age, gender, height, body weight, and cigarette smoking (packyears) were recorded. Spirometry was performed using a portable spirometer (Spirolab, Medical International Research, Rome, Italy) following the criteria from the recommendations of ATS/ERS (10). The arterial blood gases results were derived from medical recordings.

The Global Initiative for Chronic Obstructive Lung Disease (GOLD) categorizes airflow limitation into stages. In patients with the ratio of forced expiratory one second $\left(\mathrm{FEV}_{1}\right)$ / forced vital capacity (FVC) $<70 \%$, GOLD 1 -mild is $\mathrm{FEV}_{1} \geq 80 \%$ predicted; GOLD 2-moderate is $\mathrm{FEV}_{1} 50-80 \%$ predicted, GOLD 3-severe is $\mathrm{FEV}_{1} 30-50 \%$ predicted, and GOLD 4-very severe is $\mathrm{FEV}_{1}<30 \%$ predicted (11).

The DOSE Index was calculated using the MMRC dyspnea scale, predicted of forced expiratory volume in one second (FEV \%), smoking status, and exacerbation rate (8). For the exacerbation rate, the number of exacerbation frequency that they encounter in the last year was asked and recorded.

Respiratory muscle strength was measured using a portable mouth pressure device (Micro MPM, 
Micro Medical Ltd, Chatham Kent, UK). Maximal inspiratory pressure (MIP) and maximal expiratory pressure (MEP) were measured with the patient in an upright sitting position, for the evaluation of respiratory muscles. For the measurement of MIP, the patient was asked to perform a maximum inspiration and maintain it for 1-3 seconds after a maximal expiration with the closed respiratory tract using a valve. For the measurement of MEP, the patient was asked to perform maximal expiration of 1-3 seconds against closed airway after maximal inspiration. The measurements were repeated three times. The best of the three measurements was selected. There should be no more than a $10 \%$ difference between the two best-measured values.
The MIP and MEP were expressed as predicted values according to age and gender (12).

Jamar analogue hand dynamometer (PowerTrack II, JTECH Medical, Midvale, Utah, USA), has high validity and reliability and is accepted as the gold standard, was used for the measurement of handgrip strength $(13,14)$. Measurements were performed at the shoulder in adduction, and the elbow was in $90^{\circ}$ flexion, the forearm was in the neutral position while sitting. The measurements were repeated three times for the right and left sides. The highest value of both sides was recorded, and the dominant side values were used for the analysis $(13,14)$.

Table 1: Characteristics of Patients.

\begin{tabular}{|c|c|c|}
\hline \multirow{2}{*}{ Parameters } & \multicolumn{2}{|c|}{$\begin{array}{c}\text { COPD } \\
(n=45)\end{array}$} \\
\hline & Mean \pm SD & Min-Max \\
\hline Age (years) & $58.91 \pm 9.57$ & $41.00-80.00$ \\
\hline Gender (female/male) & $15 / 30$ & \\
\hline Weight (kg) & $74.70 \pm 11.05$ & $45.00-100.00$ \\
\hline Height (cm) & $165.02 \pm 8.32$ & $147.00-180.00$ \\
\hline BMI $\left(\mathrm{kg} / \mathrm{m}^{2}\right)$ & $27.56 \pm 4.64$ & $16.28-40.58$ \\
\hline Smoking (pack-years) & $34.66 \pm 28.37$ & $0-100.00$ \\
\hline \multicolumn{3}{|l|}{ Pulmonary Function Test } \\
\hline $\mathrm{FEV}_{1}(\mathrm{~L})$ & $2.30 \pm 0.77$ & $0.45-2.61$ \\
\hline FEV $_{1}(\%)$ & $50.60 \pm 16.00$ & $17.00-85.00$ \\
\hline FVC (L) & $2.30 \pm 0.77$ & $0.89-4.01$ \\
\hline FVC (\%) & $66.31 \pm 16.78$ & 27.00-106.00 \\
\hline FEV $_{1} /$ FVC (\%) & $62.91 \pm 16.36$ & $30.10-94.40$ \\
\hline PEF (L) & $4.28 \pm 2.18$ & $1.75-15.00$ \\
\hline PEF (\%) & $53.60 \pm 19.68$ & $2.29-100.00$ \\
\hline $\mathrm{FEF}_{25-75 \%}(\mathrm{~L})$ & $2.45 \pm 9.32$ & $0.08-62.00$ \\
\hline \multirow[t]{2}{*}{$\mathrm{FEF}_{25-75 \%}(\%)$} & $53.60 \pm 19.68$ & $0.60-89.00$ \\
\hline & Median & Min-Max \\
\hline Number of Annual Exacerbations (n) & 1.00 & $0-12.00$ \\
\hline DOSE Score (0-6) & 2.00 & $0-5.00$ \\
\hline MMRC (0-4) & 2.00 & $0-3.00$ \\
\hline \multicolumn{3}{|l|}{ Arterial Blood Gases } \\
\hline $\mathrm{pH}$ & 7.42 & 7.36-7.47 \\
\hline $\mathrm{PaO}_{2}(\mathrm{mmHg})$ & 67.80 & $47.20-130.00$ \\
\hline $\mathrm{PaCO}_{2}(\mathrm{mmHg})$ & 38.50 & $30.10-51.00$ \\
\hline $\mathrm{HCO}_{3}(\mathrm{mEq} / \mathrm{L})$ & 24.40 & $22.00-90.40$ \\
\hline $\mathrm{SaO}_{2}(\%)$ & 93.50 & $26.90-99.00$ \\
\hline
\end{tabular}

BMI: Body Mass Index, FEV : Forced Expiratory Volume in One Second, FVC: Forced Vital Capacity, PEF: Peak Expiratory Flow, FEF ${ }_{25-75 \%}$ : Forced Expiratory Flow from 25-75\%, DOSE: Dyspnea, Obstruction, Smoking, Exacerbation, MMRC: Modified Medical Research Council Dyspnea Scale, PaO ${ }_{2}$ : Arterial Oxygen Tension, $\mathrm{PaCO}_{2}$ : Arterial Carbon Dioxide Tension, $\mathrm{HCO}_{3}$ : Bicarbonate Concentration in Arterial Blood, $\mathrm{SaO}_{2}$ : Oxygen Saturation. 
Table 2: Descriptive Data of Respiratory Muscle and Hang Grip Strength, Physical Activity, Leisure Time Activities of Daily Living, and Health-Related Quality of Life.

\begin{tabular}{|l|c|c|}
\hline \multirow{2}{*}{ Parameters } & \multicolumn{2}{|c|}{ COPD (n=45) } \\
\cline { 2 - 3 } & Mean \pm SD & $37.00-142.00$ \\
\hline MIP (cmH $\left.\mathbf{2}_{\mathbf{0}}\right)$ & $92.04 \pm 26.11$ & $29.92-169.75$ \\
\hline MIP (\%) & $96.65 \pm 31.67$ & $47.00-269.00$ \\
\hline MEP (cmH $\mathbf{2})$ & $134.47 \pm 40.17$ & $20.23-130.24$ \\
\hline Hand Grip Strength $(\mathbf{k g})$ & $75.37 \pm 23.62$ & $7.26-47.63$ \\
\hline CAT Score (0-40) & $26.96 \pm 9.07$ & $2.00-34.00$ \\
\hline LCADL & $15.29 \pm 7.34$ & $4.00-11.00$ \\
Self-care & $6.03 \pm 1.84$ & $0.00-17.00$ \\
Domestic & $5.68 \pm 4.75$ & $2.00-9.00$ \\
Physical & $4.77 \pm 1.62$ & $2.00-10.00$ \\
Leisure & $4.38 \pm 1.68$ & $9.00-38.00$ \\
Total & $0.90 \pm 6.93$ & \\
\hline
\end{tabular}

MIP: Maximal Inspiratory Pressure, MEP: Maximal Expiratory Pressure, CAT: COPD Assessment Test, LCADL: London Chest Activity of Daily Living Scale.

The quality of life was assessed using the diseasespecific COPD Assessment Test (CAT). The CAT consists of eight questions questioning the symptoms such as shortness of breath, cough, sputum, wheezing, fatigue, and sleep status. Patients give a score of $0-5$ for each question. The total CAT score is obtained by summing the scores given to all items. The total score ranged from 0 to 40 points. Higher scores indicate more severe health status impairment or less successful control of COPD (15). The Turkish validity and reliability study of the questionnaire was conducted (16). The permission for CAT was provided.

Activities of daily living were evaluated using the London Chest Activity of Daily Living Scale (LCADL). The LCADL was developed by Garrod et al. to assess the dyspnea during daily living activities in patients with COPD (17). The LCADL consists of 15 items: personal care (4 items), housework (6 items), physical (2 items), and leisure time (3 items). Each item is given a score ranging from 0 to 5 . High scores indicate that activities of daily living are more limited. The validity and reliability study of the scale was conducted for the Turkish population (18). Permission to use the scale was provided.

\section{Statistical Analysis}

The Statistical Package for the Social Sciences version 20.0 (SPSS Statistics, IBM Corp.,
Armonk, New York, USA) was used to analyze the data. Descriptive data were used to represent participant characteristics and expressed as the mean \pm standard deviation unless stated otherwise. All variables were tested visually (histograms/ probability plots) and using Shapiro-Wilk test for normality. The minimum required sample size for the study was calculated using G*Power Software (G*Power Software version 3.1.9.3, Heinrich Heine University, Düsseldorf, Germany). For the significance assumed at 0.05 and the statistical power level as $80 \%$, the minimum required sample size for the study was calculated as 45 . The formula for calculation is based on two-tailed calculations. The relationships between the DOSE Index and hand grip and respiratory muscle strength, activities of daily living, and quality of life were assessed using Spearman's rank correlation coefficients. Correlations were classed as "strong" ( $r>0.70)$, "moderate" ( $r=0.50-0.69)$, “weak" ( $r=0.26-0.49)$, and "very weak or no correlation" ( $r=0.00-0.25)$ (19). A p-value $<0.05$ was considered statistically significant (20).

\section{RESULTS}

Forty-five patients with COPD (30 males, 15 females, mean $\mathrm{FEV}_{1}=50.60 \pm 16.00 \%$ ) participated. The flow diagram of the patients was shown in Figure 1. The characteristics of the patients were demonstrated in Table 1. According to the GOLD classification, $21(46.70 \%)$ of the patients had 
Table 3: Correlations between the Handgrip and Respiratory Muscle Strength and, Physical Activity, Leisure Time Activities of Daily Living, and Health-Related Quality of Life.

\begin{tabular}{|l|c|c|c|c|c|c|}
\hline \multicolumn{2}{|l|}{ Parameter } & $\begin{array}{c}\text { Handgrip } \\
\text { Strength }\end{array}$ & MIP & $\begin{array}{c}\text { LCADL-Physical } \\
\text { Activity }\end{array}$ & $\begin{array}{c}\text { LCADL-Leisure } \\
\text { Activities }\end{array}$ & CAT Score \\
\hline \multirow{2}{*}{$\begin{array}{l}\text { DOSE Index } \\
\text { Score }\end{array}$} & $\mathbf{r}$ & -0.388 & -0.323 & 0.314 & 0.397 & 0.435 \\
\cline { 2 - 7 } & $\mathbf{p}$ & $\mathbf{0 . 0 0 9 *}$ & $\mathbf{0 . 0 3 3 ^ { * }}$ & $\mathbf{0 . 0 3 8 ^ { * }}$ & $\mathbf{0 . 0 0 8}^{* *}$ & $\mathbf{0 . 0 0 3}^{* *}$ \\
\hline
\end{tabular}

${ }^{*} \mathrm{p}<0.05$. DOSE: Dyspnea, Obstruction, Smoking, Exacerbation, MIP: Maximal Inspiratory Pressure, LACDL: London Chest Activity of Daily Living Scale, CAT: COPD Assessment Test.

moderate COPD, and 24 (53.30\%) had severe COPD. The descriptive data of respiratory muscle strength, hand grip strength, and activities of daily living, and health-related quality of life are given in Table 2.

There was a weak correlation between the DOSE Index score and MIP values of patients with COPD $(r=-0.323, p=0.033)$. The correlation between the DOSE Index score and hand grip strength was $r=0.388(p=0.009)$. The DOSE Index score was significantly correlated with LCADL-physical activity score ( $r=0.314, p=0.038)$ and LCADLleisure activities score $(r=0.397, p=0.008)$. There was a weak relationship between the DOSE Index and CAT score $(r=0.435, p=0.003)$.

\section{DISCUSSION}

Hand grip strength and respiratory muscle strength, physical activity, leisure time activities of daily living, and health-related quality of life decrease as the multi-component disease severity increases in COPD patients. The results revealed the DOSE Index, a simple disease severity assessment tool is convenient and practical assessment tool and may reflect the impact of COPD severity on the handgrip and respiratory muscle strength, physical activity, leisure time activities of daily living, and health-related quality of life.

While there were studies investigated the association between the BODE Index and hand grip strength, there were no studies investigating the relationship between the DOSE Index and hand grip strength in the literature $(21,22)$. A strong correlation between the BODE Index and hand grip strength was reported the in moderatesevere patients with COPD in the limited number of studies $(21,23)$. According to the study of Marino et al., there was any association correlation between the BODE Index and hand grip strength, upper and lower limb strength (22). Ozsoy et al. found that hand grip and inspiratory muscle strength were not different between GOLD B (high symptom level/low exacerbation risk) and GOLD C (low symptom level/ high exacerbation risk) patients with COPD (24). Inspiratory muscle strength was demonstrated to be decreased as the severity of COPD increases that were evaluated by the BODE multidimensional index in several studies $(25-27)$. The results showed that the DOSE Index score is related to a handgrip and inspiratory muscle strength following literature findings. This shows that the dyspnea, obstruction level, exacerbation rate, and smoking exposure burden increase are related to higher disease severity, and as the disease progresses, muscle dysfunction becomes apparent. The weak association between multidimensional disease severity and other parameters may be due to no inclusion of GOLD IV COPD patients.

Patients with COPD experience, a progressive decline in the ability to perform activities of daily living during their disease and most problematic activities of daily living were reported as walking, stair climbing, and cycling (28). In our previous study with 42 moderate and severe COPD patients, we showed that the ADO Index score was significantly correlated with the LCADL-physical activity score, performance-based Glittre activities of daily living test duration, change in heart rate, oxygen saturation, and dyspnea perception during the Glittre activities of daily living test (29). In the limited number of studies, BODE Index score was strongly related to activities of daily living limitation $(21,30)$. Our findings supported the literature that higher multidimensional disease severity is related to the higher impact of dyspnea on physical activities and leisure time activities.

Jones et al. reported that the BODE Index is not available to use, the ADO Index is a better predictor of mortality than DOSE Index; however, the DOSE 
Index showed a better correlation with symptoms measures and exacerbations and hospitalizations risk in future (7). The same study reported that the DOSE Index had a stronger association than the ADO Index with health status, which was assessed using St George Respiratory Questionnaire and healthcare consumption outcomes (7). Ozsoy et al. showed that GOLD group B patients have poor CAT scores compared to group C patients (24). The present study unveiled the association between the DOSE Index and health-related quality of life that evaluated using CAT. As the disease severity increase, decreased pulmonary function, increased symptom perceptions, and exacerbation rates adversely affect the quality of life.

The present study was the first study investigating the association between the DOSE Index and peripheral and respiratory muscle strength. The study revealed the correlation between DOSE Index and CAT score which reflects the functional status of patients with COPD (31). Therefore, we may infer that the DOSE Index can be indirectly related to functional status in patients with COPD. On the other hand, one of the limitations of our study was that we did not assess the exercise capacity; for this reason, we could not analyze its correlation with the DOSE Index. The other limitation was that we did not evaluate COPD patients from all stages, and this limits the generalizability of our findings.

In conclusion, hand grip strength, inspiratory muscle strength, physical activity and leisure time activities limitation, and quality of life have an association with the DOSE Index in patients with moderate and severe COPD. This result suggests that these assessments may be used as an adjunct to the DOSE Index and may be useful to predict functional capacity for better reflecting of the deteriorating effects of COPD. The DOSE Index used as complementary for the assessments by researchers, and it may offer a comprehensive understanding of the disease and may be guiding for the researchers to decide individually tailored pulmonary rehabilitation program. The comparison of these multi-component indices regarding their association with other objective assessment parameters needs to be investigated to clarify which index is more useful in clinical practice.

\section{Sources of Support: None}

Conflict of Interest: The authors declare no conflicts of interest or potential conflicts of interest in this article.

Ethical Approval: Hacettepe University Medical, Surgical and Drug Research Ethical Committee approved this study with approval number of LUT 12/56 (The approval date: 28.08.2012).

Informed Consent: All subjects provided written informed consent.

Peer-Review: Externally peer-reviewed.

Author Contributions: Concept - EÇK, HA, Dii; Design - EÇK, HA, Dii; Supervision - HA, Dii; Resources and Financial Support - EÇK, HA, Dii; Materials - EÇK, NVY, MS; Data Collection and/or Processing - AÇ, HT; Analysis and/or Interpretation - AÇ, HT; Literature Research - AÇ, CBÖ, HSU; Writing Manuscript - AÇ, EÇK, NVY, MS; Critical Review - EÇK, HA, Dii, çÖ, SS, TD, LÇ.

Acknowledgements: None.

\section{REFERENCES}

1. Vogelmeier CF, Criner GJ, Martinez FJ, Anzueto A, Barnes PJ, Bourbeau J, et al. Global Strategy for the Diagnosis, Management and Prevention of Chronic Obstructive Lung Disease 2017 Report: GOLD Executive Summary. Respirology. 2017;22(3):575601.

2. Agusti A. Systemic effects of chronic obstructive pulmonary disease: what we know and what we don't know (but should). Proc Am Thorac Soc. 2007;4(7):522-5.

3. Choudhury G, Rabinovich R, MacNee W. Comorbidities and systemic effects of chronic obstructive pulmonary disease. Clin Chest Med. 2014;35(1):101-30.

4. Alter A, Aboussouan LS, Mireles-Cabodevila E. Neuromuscular weakness in chronic obstructive pulmonary disease: chest wall, diaphragm, and peripheral muscle contributions. Curr Opin Pulm Med. 2017;23(2):129-38.

5. van Helvoort HA, Willems LM, Dekhuijzen PR, van Hees HW, Heijdra YF. Respiratory constraints during activities in daily life and the impact on health status in patients with early-stage COPD: a cross-sectional study. NPJ Prim Care Respir Med. 2016;26:16054.

6. Wacker ME, Hunger M, Karrasch S, Heinrich J, Peters A, Schulz $\mathrm{H}$, et al. Health-related quality of life and chronic obstructive pulmonary disease in early stages - longitudinal results from the population-based KORA cohort in a working age population. BMC Pulm Med. 2014;14:134.

7. Jones RC, Price D, Chavannes NH, Lee AJ, Hyland ME, Stallberg $B$, et al. Multi-component assessment of chronic obstructive pulmonary disease: an evaluation of the ADO and DOSE indices and the global obstructive lung disease categories in international primary care data sets. NPJ Prim Care Respir Med. 2016;26:16010.

8. Jones RC, Donaldson GC, Chavannes NH, Kida K, Dickson- 
Spillmann M, Harding S, et al. Derivation and validation of a composite index of severity in chronic obstructive pulmonary disease: the DOSE Index. Am J Respir Crit Care Med. 2009;180(12):1189-95.

9. Rolink M, van Dijk W, van den Haak-Rongen S, Pieters W, Schermer T, van den Bemt L. Using the DOSE index to predict changes in health status of patients with COPD: a prospective cohort study. Prim Care Respir J. 2013;22(2):169-74.

10. Miller MR, Hankinson J, Brusasco V, Burgos F, Casaburi R, Coates $\mathrm{A}$, et al. Standardisation of spirometry. Eur Respir J. 2005;26(2):319-38.

11. Global Initiative for Chronic Obstructive Lung Disease (GOLD). Global strategy for the diagnosis, management, and prevention of chronic obstructive pulmonary disease 2018 Report. http:// www.goldcopd.org/. Access Date: June 11, 2019.

12. Black LF, Hyatt RE. Maximal respiratory pressures: normal values and relationship to age and sex. Am Rev Respir Dis. 1969;99(5):696-702.

13. Schmidt RT, Toews JV. Grip strength as measured by the Jamar dynamometer. Arch Phys Med Rehabil. 1970;51(6):321-7.

14. Shechtman O, Gestewitz L, Kimble C. Reliability and validity of the DynEx dynamometer. J Hand Ther. 2005;18(3):339-47.

15. Jones PW, Harding G, Berry P, Wiklund I, Chen WH, Kline Leidy N Development and first validation of the COPD Assessment Test. Eur Respir J. 2009;34(3):648-54

16. Yorgancioglu A, Polatli M, Aydemir O, Yilmaz Demirci N, Kirkil G, Nayci Atis S, et al. Reliability and validity of Turkish version of COPD assessment test. Tuberk Toraks. 2012;60(4):314-20.

17. Garrod R, Bestall JC, Paul EA, Wedzicha JA, Jones PW. Development and validation of a standardized measure of activity of daily living in patients with severe COPD: the London Chest Activity of Daily Living scale (LCADL). Respir Med. 2000;94(6):589-96.

18. Met S. Obstrüktif Akciğer Hastalarında London Chest Günlük Yaşam Aktiviteleri Ölçeğinin Geçerlik ve Güvenirliğinin ve Fiziksel Aktivite Düzeylerinin Belirlenmesi. Bilim Uzmanlığı Tezi, Hacettepe Üniversitesi, Ankara, 2009.

19. Domholdt E. Physical therapy research: principles and applications. 2nd ed. Philadelphia: WB Saunders; 2000.

20. Hayran M, Hayran M. Sağlık araştırmaları için temel istatistik. 1. Baskı. Ankara: Omega Araştırma Organizasyon Eğitim Danışmanlık Ltd.; 2011.
21. Mahadevan R SP, Chaya SK. Association of BODE index to daily living activities and upper limb strength in chronic obstructive pulmonary disease. Int J Health Allied Sci. 2015;4(4):243-6.

22. Marino DM, Marrara KT, Ike D, De Oliveira AD, Jr., Jamami M, Di Lorenzo VA. Study of peripheral muscle strength and severity indexes in individuals with chronic obstructive pulmonary disease. Physiother Res Int. 2010;15(3):135-43.

23. Regueiro EM, Di Lorenzo VA, Basso RP, Pessoa BV, Jamami $\mathrm{M}$, Costa D. Relationship of BODE Index to functional tests in chronic obstructive pulmonary disease. Clinics (Sao Paulo). 2009;64(10):983-8.

24. Ozsoy I, Acar S, Ozalevli S, Akkoclu A, Savci S. Chronic Obstructive pulmonary disease Group B and C: are they really the opposite of each other regarding exercise capacity and muscle strength? Turk J Physiother Rehabil. 2018;29(2):18-23.

25. Kabitz HJ, Walterspacher S, Walker D, Windisch W. Inspiratory muscle strength in chronic obstructive pulmonary disease depending on disease severity. Clin Sci (Lond). 2007;113(5):2439.

26. Ju C, Liu W, Chen RC. Twitch mouth pressure and disease severity in subjects with COPD. Respir Care. 2014;59(7):1062-70.

27. Donaria L, Mesquita R, Martinez L, Sipoli L, Felcar JM, Probst VS, et al. Relationship between sniff nasal inspiratory pressure and BODE index in patients with COPD. Lung. 2014;192(6):897-903.

28. Annegarn J, Meijer K, Passos VL, Stute K, Wiechert J, Savelberg $\mathrm{HH}$, et al. Problematic activities of daily life are weakly associated with clinical characteristics in COPD. J Am Med Dir Assoc. 2012;13(3):284-90.

29. Calik-Kutukcu E AH, Saglam M, Vardar-Yagli N, Inal-Ince D, Oksuz C, Savci S, Duger T, Coplu L. An investigation of the relationship between multidimensional disease severity and activities of daily living in patients with chronic obstructive pulmonary disease. J Exerc Ther Rehabil. 2015;2(2):53-60.

30. Simon KM, Carpes MF, Correa KS, dos Santos K, Karloh M, Mayer AF. Relationship between daily living activities (ADL) limitation and the BODE index in patients with chronic obstructive pulmonary disease. Rev Bras Fisioter. 2011;15(3):212-8.

31. Gulart AA, Munari AB, Queiroz AP, Cani KC, Matte DL, Mayer AF. Does the COPD assessment test reflect functional status in patients with COPD? Chron Respir Dis. 2017;14(1):37-44 